\title{
Pedagogical Perceptions and Attitudes of Saudi Arabia University Students Towards Adopting WhatsApp As Students-teachers' Interactive Tool
}

\author{
Amir Mohammed Albloy ${ }^{1}$, Wijdan Mohieldeen Mohamed $^{2}$ \\ Najran University ${ }^{1}$, Qassim University ${ }^{2}$ \\ Saudi Arabia
}

\begin{abstract}
This study was mainly grounded in the researchers' personal experience of using WhatsApp as an interaction tool in an English classroom. This platform was used to enhance the communicative interaction between the students and their teachers. WhatsApp group was created during the first semester in 2018/2019 at the College of Science and Arts at Najran University - Branch of Sharurah, and the College of Sciences \& Arts at Qassim University - Branch of Alasyah. The participants were bachelor's degree students of English. The study employed a quantitative exploratory research approach, whereby a questionnaire was distributed to students who used WhatsApp as an interactive tool in their course of study. Data was obtained through a questionnaire with (40) purposively selected students of WhatsApp group. Data were analyzed quantitatively based on the SPSS program. The results show that WhatsApp had a positive effect in enhancing interaction between students and their teachers, WhatsApp makes interaction between teachers \& their students easier than in the classroom. As a result, shy students can freely communicate \& interact through WhatsApp with each other and their teachers, WhatsApp creates a friendly relationship between students and their teacher, and WhatsApp is an efficient tool of interaction in cases of distant learning. Therefore, student-teacher interaction becomes more effective in WhatsApp than inside the classroom.
\end{abstract}

\section{Introduction}

The popularity of SNSs among university students might suggest that they would be suitable and valuable tools which could be used for educational purposes. SNSs have been used to: facilitate online and blended education; provide easy and flexible access to educational materials; provide students with administrative information; facilitate communication among students and between students and instructors; replace learning management systems; and motivate students. The use of SNSs has great potential in higher education in developing countries because of their availability and affordability.

WhatsApp like other social media platforms constitutes several features which contribute to the learning process, such as encouraging collaborative learning, active participation in class, learning any time, any place, enhancing relationships, improving learning, motivation and offering personalized course material. [1] However, research reveals that this tool isn't widely implemented. [2] Therefore, the aim of this paper is to explore classroom communication between lecturers and students using WhatsApp at the College of Business Education (CBE) in Tanzania, probing on the benefits and challenges encountered by students' and future implications for the use of WhatsApp as a platform for classroom communication are discussed.

\section{Objectives of The Study}

Exploring the students' perceptions and attitudes towards the possibility of integrating WhatsApp as a tool of interaction, is the core aim of the current article as well as to fulfill the following objectives:

1. To identify the capability of WhatsApp use as a tool of interaction between students and teachers.

2. To find out how WhatsApp can create a friendly rapport between teachers and students.

\section{Statement of the Problem}

Once class interaction is the flavor of learning in teaching and learning languages. It was observed that the majority of learners of English still do have some barriers that inhibit them of directly interact with the teacher inside the class this case was quietly different as observed by the researchers when the students attached them to their WhatsApp group in which the students actively and effectively contact with their teachers with no hesitation, reluctant, and even shy students found their opportunity to contact with the teacher. These indications stimulated the researchers to reveal the reality of the students' feelings and experience about the analogy of methods of interaction inside class and WhatsApp group this is which the article deeply going to investigate.

\section{Research Questions and Hypotheses}

The main purpose of this article was to explore the students' perceptions and attitudes towards using WhatsApp as a tool of interaction between them and their teachers. Thus, in order to achieve its aims, the following questions should be answered: 
1. To what extent can WhatsApp be an efficient tool of interaction between students and their teacher?

2. In what way can WhatsApp create a friendly rapport between students and their teacher?

In support of finding answers to the above questions, the following hypotheses were posed as follows:

H1: WhatsApp is an efficient tool of interaction between the students and their teacher.

$\mathrm{H} 2$ : WhatsApp creates a friendly rapport between the teacher $\&$ the students.

\section{Literature Review}

Social Networking Sites (SNSs) are very popular among university students. The use of different types of SNSs is common among university students in different parts of the world. For instance, [3] found that $92.6 \%$ of 282 university students who participated in a study in a university in Jordan reported using Facebook. [4] found that $89 \%$ of 300 students who participated in a study in a university in Kuwait reported using Twitter. In a large-scale study [5] found that $100 \%$ of 875 students from universities in the United States and in Europe reported using different types of SNSs. Students commonly use their smart phones to access their SNSs. [6] This enables them to use SNSs anytime and anywhere. Social Networks have been used for a variety of purposes including communication, exchanging media, and entertainment. [7] SNSs are easy, cheap, convenient, reliable, entertaining, and they can be accessed anywhere. Furthermore, university the social norms and cultural constraints that are present in gender-segregated societies.

Recently, social media has exploded as a category of an online platform where people create content, share it, bookmark it and network at a high rate. [8] The use of social media has become common among people of different age groups. What used to be a hobby for some people has now become a style of life. Young people have embraced social media as a platform for communication and sharing information. [9] These technologies are known to act as an indispensable role in collaboration, community building, and participation. Even though they are somehow structurally different, social media platforms that have become a part of users' daily lives, they are now used in education [10]. And they are changing the ways knowledge is digested and taught in classrooms by providing teachers and students new avenues for communication, curriculum delivery, and learning. [11]

According to [12], social media is the use of Facebook, Blogs, Twitter, MySpace, and LinkedIn for the purpose of communication, sharing photos as well as videos. However, for the purpose of this study social media is captured by the use of the internet through WhatsApp for communication, sharing of ideas, study materials, assignments, coursework results, and links by students and teachers. WhatsApp is a Smartphone application that runs on most devices which allow people to create groups and communicate within its boundaries. One of the unique features of this application is its ability to enhance communication within a group of people that makes it the most widely downloaded applications having more than 600 million users globally. [13] This communication tool has quickly become pervasive and popular among tertiary education students. [14] There are various reasons explaining why people adopt WhatsApp as their main communication tool. Bouhnik and Deshen note the following: The low cost of the application, the ability to send an unlimited number of messages, the immediacy, the desire to feel a part of the trend since their acquaintances have already adopted the application, the capacity to conduct an on-going conversation with many friends simultaneously, the knitting together of a community of friends or family, and a sense of privacy relative to other social networks [2].

WhatsApp can be used in higher education in a number of ways to achieve different educational goals. For instance, [15] argued that WhatsApp can be used in higher education to create immediate connections, encourage reflection, and facilitate coordination in informal and formal learning. [16] found that WhatsApp was a useful electronic tool to facilitate information sharing among university students on a range of subjects related to the courses that they were studying. The author reported that WhatsApp served as a tool for bridging access to learning resources, rendering peer-based and hierarchical support, leveraging on-task behavior and enhancing meaningful context-free learning. [17] found that WhatsApp can be useful in language assessment. Students can use WhatsApp to record their speech and share their recordings with their teachers and other students. [18] examined the effect of the use of WhatsApp on English as Foreign Language (EFL) students in written vocabulary tasks in Saudi Arabia. The author found that WhatsApp had a positive effect on students' performances. The students enjoyed using WhatsApp as a learning tool. They perceived the use of WhatsApp as a game rather than a formal class requirement. [19] reported that WhatsApp can be used to facilitate mobile learning. In their study, the students used WhatsApp as a communication tool outside the classroom to exchange information about meetings and projects. [20] found that the use of WhatsApp to facilitate blended learning had a positive and significant impact on students' learning performance and their attitudes toward blended learning. [21] examined college of education students' experiences of WhatsApp mobile learning and found that the use of 
WhatsApp increased students' social interactivity with each other and with the instructor, and this facilitated collaborative learning. In addition, the authors found that students had positive attitudes toward the use of WhatsApp in their leaning. [22] found that WhatsApp could be useful to create alternative dialogic spaces for student collaborative engagements in informal contexts, which can gainfully transform teaching and learning. [23] reported that WhatsApp had been used in different academic disciplines to support students' learning.

These academic disciplines included education, mathematics, information systems, and languages. The educational advantages of WhatsApp, students' positive attitudes towards its use, and its popularity suggest that WhatsApp has significant potential for use in higher education. In developing countries, university students have limited access to expensive technologies such as desktop and laptop computers. The use of WhatsApp in education does not require special infrastructure. University students own the hardware (i.e., smartphones) and they can download the software (i.e., the WhatsApp application) for free. WhatsApp can be used for teaching and learning to bridge the digital divide among students.

Some research studies have examined university students' use of WhatsApp. [24] examined higher education students' use of WhatsApp. Four hundred and eighteen students completed a questionnaire. The results showed that most were heavy users of WhatsApp. More than $96 \%$ of the participants reported using it for more than three hours a day. Most participants used WhatsApp for chatting while only $7 \%$ reported using it for academic work.

Students' perceptions of the use of WhatsApp in their educational processes have been examined in some studies. For instance, [25] examined students' perceptions of the use of WhatsApp as a learning tool in a university in Malaysia. A qualitative research design was followed in which interviews were conducted with some students. The results showed that the students believed that WhatsApp could be helpful in their learning by facilitating communication with other students and with the instructor, collaborative learning, and access to and sharing of educational information. WhatsApp can be used as a medium for learning and teaching the English language. However, the students in [25] study believed that the use of WhatsApp as a learning tool had the following limitations: it did not involve face-to-face communication, it was timeconsuming, there was a risk of miscommunication, it was constrained by the rules of phone etiquette, it was dependent on Wi-Fi connections, and it could not be used by individuals who had their phones on silent mode.

In Hong Kong, [26] found that university students who had experience with the formal use of WhatsApp to support their learning, and those who had no experience with the use of WhatsApp for learning, had positive perceptions of its use to support teaching and learning in higher education. The students agreed that WhatsApp can be a useful learning tool. Examples of reported possible advantages of the use of WhatsApp for students' learning included: providing immediate messaging support, bringing new opportunities of learning, facilitating communication between students and teachers, enabling fast feedback in learning, providing flexible learning, supporting multimedia learning, and supporting collaborative learning. However, the participants said that the use of WhatsApp in their learning might interfere with their private lives.

Smartphones and their apps can be beneficial for disadvantaged universities and for countries that suffer from limited budgets and a shortage of computer labs. WhatsApp is a commonly available, popular, and affordable electronic tool. It has been integrated into university students' learning in different ways to accomplish diverse educational tasks. It provides several educational advantages for university students.

\section{Methods and Materials}

A quantitative research method was used in this study. Data were collected using a questionnaire to measure the university students' perceptions and attitudes towards the integration of WhatsApp as an interactive students-teachers tool.

\subsection{Participants}

The participants shared in this study were bachelor degree female students of English at the College of Science \& Arts at Najran UniversityBranch of Sharurah, and the College of Sciences and Arts at Qassim University-branch of Alaasyah, whose number is (40) majoring English in the second year of their enrolment.

\subsection{Instrument}

The data collection tool was a paper-based questionnaire. The questionnaire consisted of four sections that were designed to explore students' perceptions and attitudes towards the integration of WhatsApp as a student-teacher interactive tool. The options for responses in the perceptions section were strongly disagree, disagree, undecided, agree, and strongly agree representing Likert Scale method. The statements were based on the researchers' observations and previous research studies.

\subsection{Procedure}


A class that was available to all students in the university was randomly selected for the study. The class was offered as an elective unit, and female students from two different Universities inside the Kingdom of Saudi Arabia participated in the study. The researchers consulted the students agreed to participate in discussing the aim of the study and the use of WhatsApp as an interactive learning tool. Consequently, copies of the questionnaires were sent to the students who responded in due time and finally by collected by the researchers electronically via emails.

\subsection{Reliability and Validity of the Questionnaire}

In order to check the validity of the questionnaire, the researchers ran a pilot study, where four copies of the questionnaire were distributed to some of EFL teachers, they filled in the questionnaire and wrote down their comments at the end of the questionnaire. According to their comments, the number of statements was reduced from twenty in the pilot questionnaire to 10 statements. Also, some of the statements were modified.

Alpha Cronbach formula is used to compute the reliability of the questionnaire. The value of reliability lies between 0 and 1 . The reliability increases according to the increase of alpha value up to 1 . Generally, if the alpha value is more than or equal 0.4 the reliability is considered, and the questionnaire is reliable. For this study, it was found that 0.97 , and this means the questionnaire has a high reliability.

\subsection{Data Analysis}

Frequency distributions were used to highlight participants' views, to verify the hypotheses of the study in relation to participants' use of WhatsApp for interaction with their teachers. Furthermore, the Descriptive statistics through SPSS program in the form of means and standard deviations were used to verify the hypotheses and to answer the questions posed by the researchers regarding students' perceptions of the integration of WhatsApp in communicating with their teachers.

Table 1 shows that $57.5 \%$ strongly agree with the statement, and $40 \%$ agree, whereas $2.5 \%$ disagreed. Thus, the students virtually agreed that WhatsApp makes interaction between students and their teacher easier than in the classroom.
Table 1. S1: "WhatsApp makes interaction between students and their teacher easier than in the classroom"

\begin{tabular}{|c|c|c|}
\hline Options & Frequency & Percent (\%) \\
\hline Strongly agree & 23 & 57.5 \\
\hline Agree & 16 & 40.0 \\
\hline Neutral & 0 & 0.0 \\
\hline Disagree & 1 & 2.5 \\
\hline Strongly disagree & 0 & 0.0 \\
\hline Total & 40 & 100.0 \\
\hline
\end{tabular}

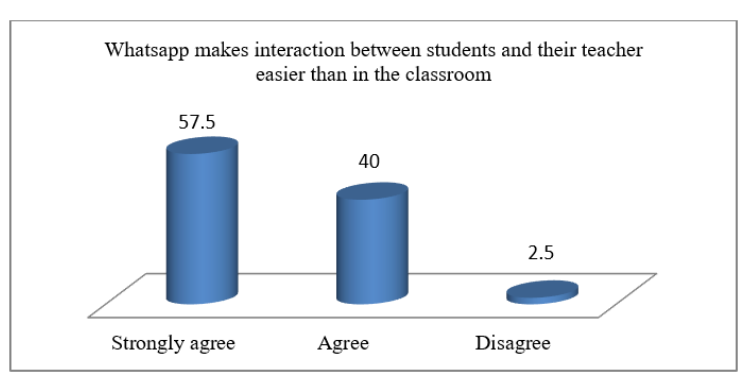

Chart 1. Comparative analysis of Question 1 responses

Table 2 shows that $65 \%$ strongly agree with the statement, and $32.5 \%$ agree, whereas $2.5 \%$ were neutral. Thus, the students unanimously agreed that the students feel more comfortable with the teacher when they need help and ask for feedback.

Table 2. S2: "The students feel more comfortable with the teacher when they need help and ask for feedback"

\begin{tabular}{|c|c|c|}
\hline Options & Frequency & Percent (\%) \\
\hline Strongly agree & 26 & 65.0 \\
\hline Agree & 13 & 32.5 \\
\hline Neutral & 1 & 2.5 \\
\hline Disagree & 0 & 0.0 \\
\hline Strongly disagree & 0 & 0.0 \\
\hline Total & 40 & 100.0 \\
\hline
\end{tabular}

The students feel more comfortable with teacher when they need help and ask for feedback

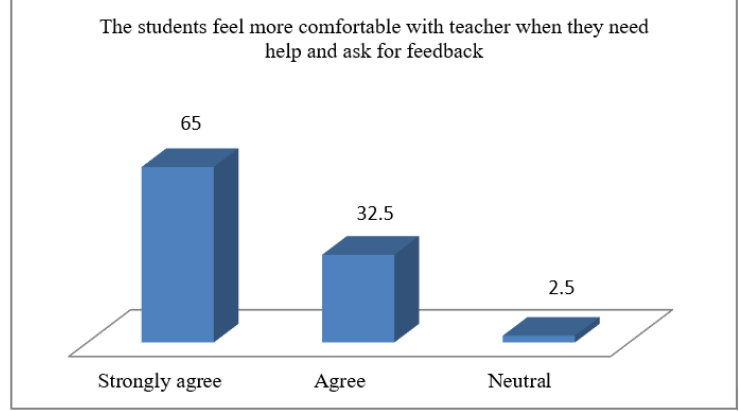

Chart 2. Comparative analysis of Question 2 responses 
Table 3. S3: WhatsApp puts the students with their teacher in a constant communicative setting

\begin{tabular}{|c|c|c|}
\hline Options & Frequency & Percent (\%) \\
\hline Strongly agree & 13 & 32.5 \\
\hline Agree & 20 & 50.0 \\
\hline Neutral & 7 & 17.5 \\
\hline Disagree & 0 & 0.0 \\
\hline Strongly disagree & 0 & 0.0 \\
\hline Total & 40 & 100.0 \\
\hline
\end{tabular}

Table 3 shows that 50 agreed with the statement, and $32.5 \%$ strongly agreed, whereas $17.5 \%$ were neutral. Thus, the students virtually agreed that WhatsApp puts the students with their teacher in a constant communicative setting.

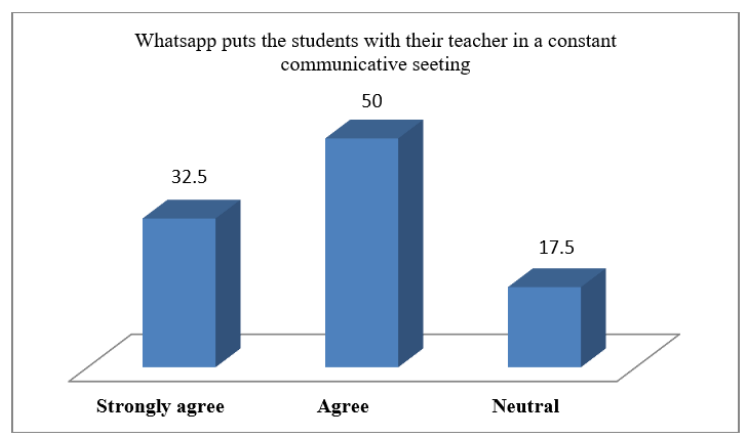

Chart 3: Comparative analysis of Question 3 responses

Table 4 shows that 50 strongly agree with the statement, and $42.5 \%$ agree, whereas $7.5 \%$ were neutral. Thus, the students unanimously agreed that shy students can freely communicate and interact through WhatsApp with each other and their teachers.

Table 4. S4: Shy students can freely communicate and interact through WhatsApp with each other and their teacher

\begin{tabular}{|c|c|c|}
\hline Options & Frequency & Percent (\%) \\
\hline Strongly agree & 20 & 50.0 \\
\hline Agree & 17 & 42.5 \\
\hline Neutral & 3 & 7.5 \\
\hline Disagree & 0 & 0.0 \\
\hline Strongly disagree & 0 & 0.0 \\
\hline Total & 40 & 100.0 \\
\hline
\end{tabular}

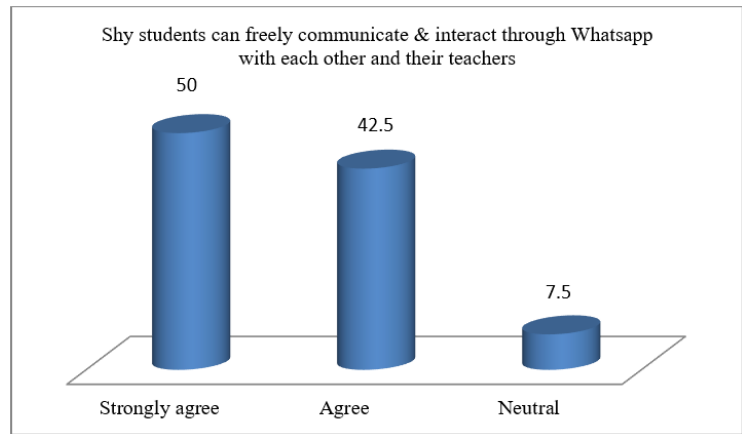

Chart 4. Comparative analysis of Question 4 responses

Table 5 shows that $52.5 \%$ strongly agreed with the statement, and $35 \%$ agreed, $7.5 \%$ neutral, whereas $5 \%$ disagreed. Thus, the majority of students agreed that WhatsApp creates a friendly rapport between the teacher and the students. These views provided by students verify the second hypothesis reads that "WhatsApp creates a friendly rapport between students and their teacher".

Table 5. S5: WhatsApp creates a friendly rapport between students and teacher

\begin{tabular}{|c|c|c|}
\hline Options & Frequency & Percent (\%) \\
\hline Strongly agree & 21 & 52.5 \\
\hline Agree & 14 & 35.0 \\
\hline Neutral & 3 & 7.5 \\
\hline Disagree & 2 & 5.0 \\
\hline Strongly disagree & 0 & 0.0 \\
\hline Total & 40 & 100.0 \\
\hline
\end{tabular}

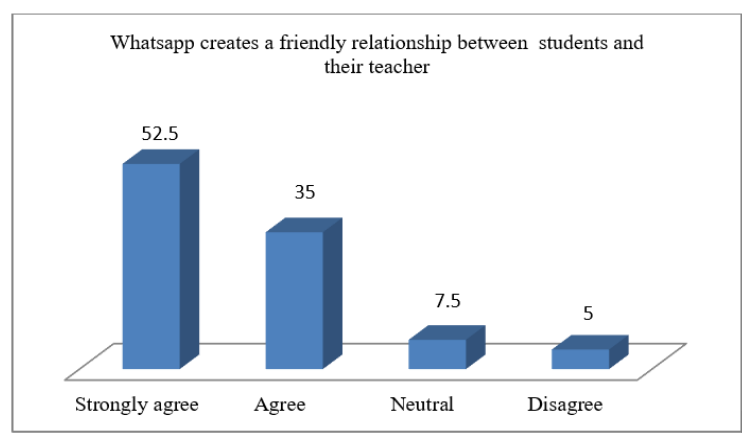

Chart 5. Comparative analysis of Question 5 responses

Table 6 shows that $35 \%$ strongly agreed with the statement, and $30 \%$ were neutral, $25 \%$ agreed, $7.5 \%$ disagreed, whereas $2.5 \%$ strongly disagreed. Thus, the majority of students agreed that The teacher students become more effective in WhatsApp than inside the classroom. 
Table 6. S6: The teacher-student interaction becomes more effective in WhatsApp than inside the classroom

\begin{tabular}{|c|c|c|}
\hline Options & Frequency & Percent (\%) \\
\hline Strongly agree & 14 & 35.0 \\
\hline Agree & 10 & 25.0 \\
\hline Neutral & 12 & 30 \\
\hline Disagree & 3 & 7.5 \\
\hline Strongly disagree & 1 & 2.5 \\
\hline Total & 40 & 100.0 \\
\hline
\end{tabular}

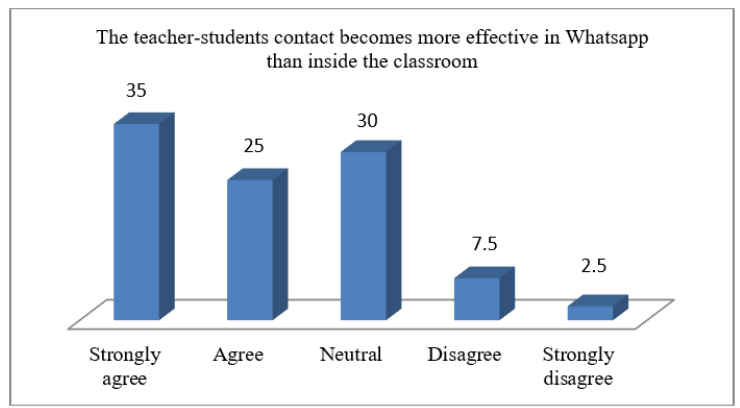

Chart 6. Comparative analysis of Question 6 responses

Table 7 shows that $57.5 \%$ agree with the statement, and $42.5 \%$ strongly agreed. Thus, the students unanimously agreed that WhatsApp is an efficient tool of interaction between the students and their teacher. These rates positively confirmed the first hypothesis that "WhatsApp is an efficient tool of interaction between the students and their teacher".

Table 7. S7: WhatsApp is an efficient tool of interaction between the students and their teacher

\begin{tabular}{|c|c|c|}
\hline Options & Frequency & Percent (\%) \\
\hline Strongly agree & 17 & 42.5 \\
\hline Agree & 23 & 57.5 \\
\hline Neutral & 0 & 0.0 \\
\hline Disagree & 0 & 0.0 \\
\hline Strongly disagree & 0 & 0.0 \\
\hline Total & 40 & 100.0 \\
\hline
\end{tabular}

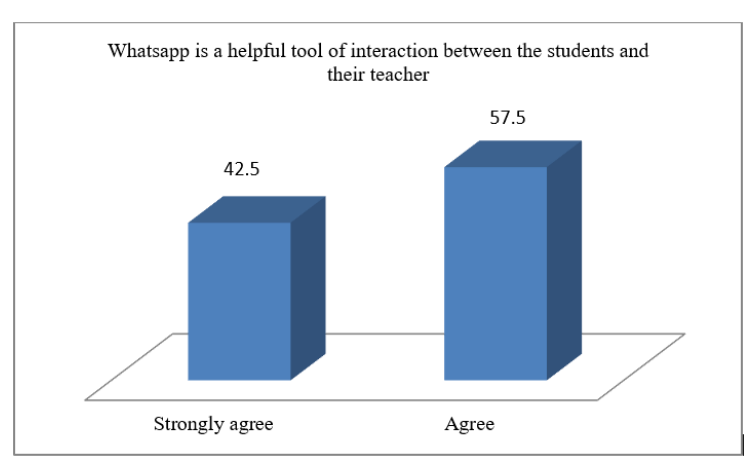

Chart 7. Comparative analysis of Question 7 responses
Table 8 shows that $52.5 \%$ strongly agreed with the statement, and 40\% agreed, 5\% disagreed, whereas $2.5 \%$ are neutral. Thus, the majority of students agreed that through WhatsApp teachers can be more familiar with their students' limits and disabilities of interaction.

Table 8. S8: Through WhatsApp, teachers can be more familiar with their students' limits and disabilities of interaction

\begin{tabular}{|c|c|c|}
\hline Options & Frequency & Percent (\%) \\
\hline Strongly agree & 21 & 52.5 \\
\hline Agree & 16 & 40.0 \\
\hline Neutral & 1 & 2.5 \\
\hline Disagree & 2 & 5.0 \\
\hline Strongly disagree & 0 & 0.0 \\
\hline Total & 40 & 100.0 \\
\hline
\end{tabular}

Through Whatsapp teachers can be more familiar with their students limits and disabilities of interaction

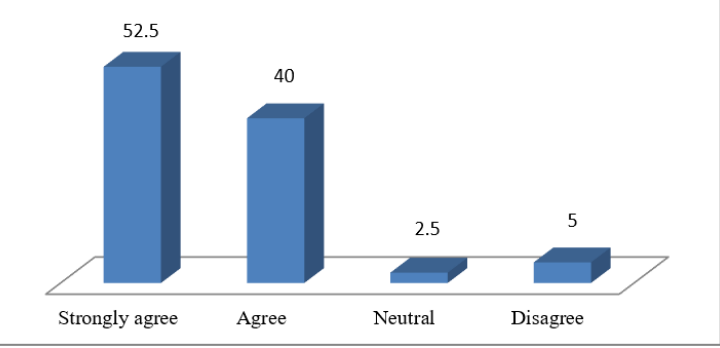

Chart 8. Comparative analysis of Question 8 responses

Table 9 shows that $42.5 \%$ of students strongly agreed with the statement, and $35 \%$ agreed, $12.5 \%$ disagreed, whereas $10 \%$ were neutral. This, in fact, indicates that supports the possibility of using WhatsApp in some circumstances of distant learning.

Table 9. S9: WhatsApp is an effective tool of interaction in cases of distant learning

\begin{tabular}{|c|c|c|}
\hline Options & Frequency & Percent (\%) \\
\hline Strongly agree & 17 & 42.5 \\
\hline Agree & 14 & 35.0 \\
\hline Neutral & 4 & 10.0 \\
\hline Disagree & 5 & 12.5 \\
\hline Strongly disagree & 0 & 0.0 \\
\hline Total & 40 & 100.0 \\
\hline
\end{tabular}




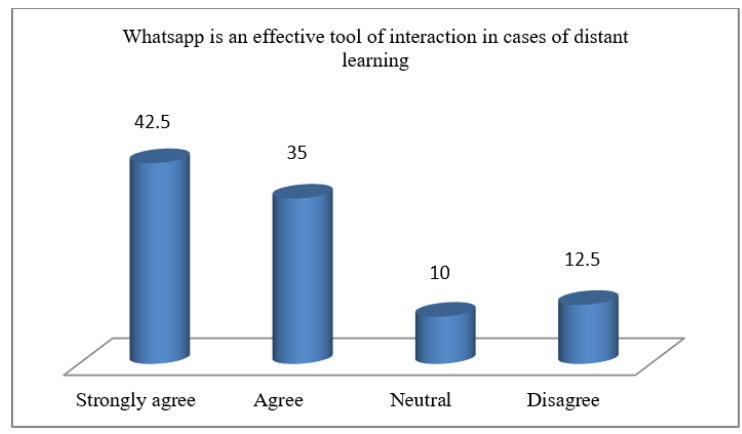

Chart 9: Comparative analysis of Question 9 responses

Table 10 reflects that $50 \%$ of the students strongly agreed with the statement, and $30 \%$ agreed, $15 \%$ were neutral, whereas $5 \%$ disagreed. Thus, the majority of the students agree with the statement that WhatsApp can help teachers observe and control the progress of their students.

Table 10. S10: WhatsApp can help teachers observe and control the progress of their students

\begin{tabular}{|c|c|c|}
\hline Options & Frequency & Percent (\%) \\
\hline Strongly agree & 20 & 50.0 \\
\hline Agree & 12 & 30.0 \\
\hline Neutral & 6 & 15.0 \\
\hline Disagree & 2 & 5.0 \\
\hline Strongly disagree & 0 & 0.0 \\
\hline Total & 40 & 100.0 \\
\hline
\end{tabular}

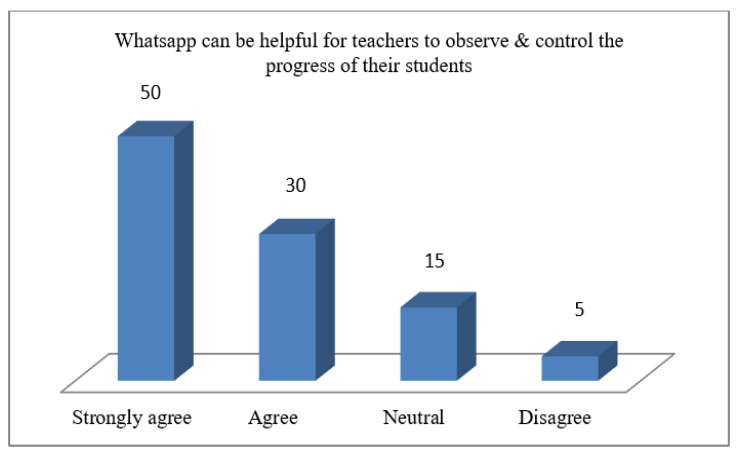

Chart 10. Comparative analysis of Question 10 responses

The average of all tabulated above responses is (4.31) and the standard deviation is (0.76). This proves that the majority of respondents agreed with all statements and consequently confirms and verifies the hypotheses of the study.
Figure 1 manifests the group of WhatsApp the students and their teacher used for online interaction.

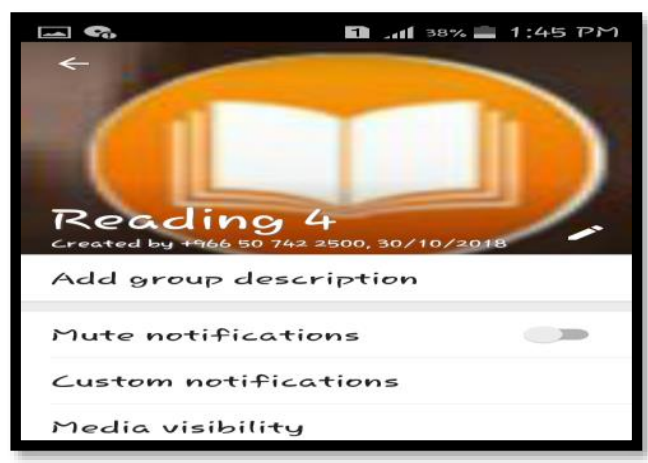

Figure 1. The group of WhatsApp

Figure 2 presents the membership of WhatsApp group.

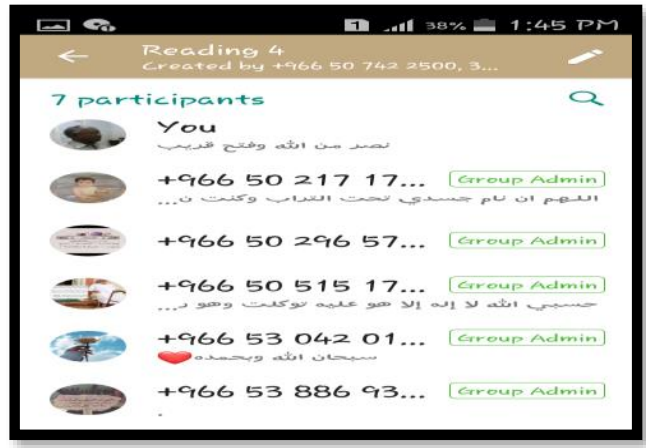

Figure 2. Membership

Figure 3 reflects the student-teacher interaction via the WhatsApp group.

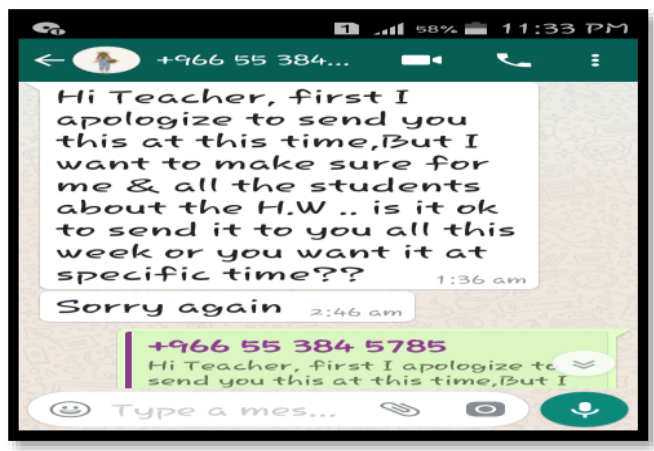

Figure 3. The student-teacher interaction 
Table 11. Mean and Standard Deviation of the students' responses to the Questionnaire

\begin{tabular}{|c|c|c|c|}
\hline Statement & Mean & Std. Deviation & Ranking \\
\hline $\begin{array}{l}\text { 1. WhatsApp makes interaction between teachers } \\
\text { and their students easier than in the classroom }\end{array}$ & 4.53 & 0.64 & 2 \\
\hline $\begin{array}{l}\text { 2. The students feel more comfortable with the } \\
\text { teacher when they need help and ask for } \\
\text { anything }\end{array}$ & 4.63 & 0.54 & 1 \\
\hline $\begin{array}{l}\text { 3. WhatsApp puts the students with their teacher } \\
\text { in a constant communicative setting }\end{array}$ & 4.15 & 0.70 & 8 \\
\hline $\begin{array}{l}\text { 4. Shy students can freely communicate and } \\
\text { interact through WhatsApp with each other and } \\
\text { their teachers }\end{array}$ & 4.43 & 0.64 & 3 \\
\hline $\begin{array}{l}\text { 5. WhatsApp creates a friendly relationship } \\
\text { between the teacher and the students. }\end{array}$ & 4.35 & 0.83 & 6 \\
\hline $\begin{array}{l}\text { 6. The teacher-students interaction becomes } \\
\text { more effective in WhatsApp than inside the } \\
\text { classroom }\end{array}$ & 3.83 & 1.08 & 10 \\
\hline $\begin{array}{l}\text { 7. WhatsApp is a helpful tool of interaction } \\
\text { between the teacher and the students }\end{array}$ & 4.43 & 0.50 & 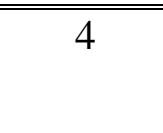 \\
\hline $\begin{array}{l}\text { 8. Through WhatsApp, teachers can be more } \\
\text { familiar with their students' limits and abilities of } \\
\text { interaction }\end{array}$ & 4.40 & 0.78 & 5 \\
\hline $\begin{array}{l}\text { 9. WhatsApp is an effective tool of interaction in } \\
\text { cases of distant learning }\end{array}$ & 4.08 & 1.02 & 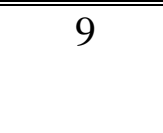 \\
\hline $\begin{array}{l}\text { 10. WhatsApp can help teachers observe and } \\
\text { control the progress of their students }\end{array}$ & 4.25 & 0.90 & 7 \\
\hline Total Mean and Standard Deviation & 4.31 & 0.76 & \\
\hline
\end{tabular}


Figure 4 shows the students-teacher instant interaction via the WhatsApp group.

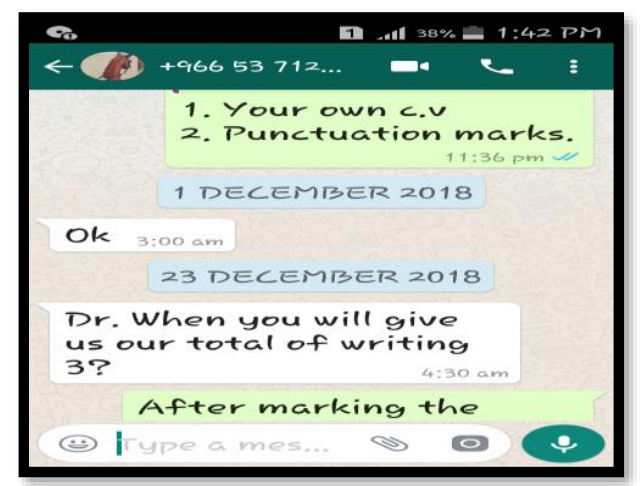

Figure 4. The example of the student-teacher instant interaction

\section{Results And Discussion}

Having accomplished the whole study, the researchers come out with the following results as stated below with their statistical rates:

The students feel more comfortable with the teacher when they need help and ask for feedback. The average responses to this statement (4.63) whereas the standard deviation is $(0.54)$. This result was supported by [26] study conducted in Hong Kong (2016) which proved that the students agreed that WhatsApp can be a useful learning tool. Examples of reported possible advantages of the use of WhatsApp for students' learning included: providing immediate messaging support, bringing new opportunities of learning, facilitating communication between students and teachers, enabling fast feedback in learning

WhatsApp makes interaction between teachers and their students easier than in the classroom. The average response to this statement is (4.53) whereas the standard deviation is (0.64). As a result, shy students can freely communicate and interact through WhatsApp with each other and their teachers. The average response to this statement is (4.43) whereas the standard deviation (0.64).

WhatsApp is an effective tool of interaction between the teacher and the students. The average responses to this statement (4.43) whereas the standard deviation is $(0.50)$. This result was in favor of a study conducted by [25] whose results showed that the students believed WhatsApp could be helpful in their learning by facilitating: communication with other students and with the instructor, collaborative learning, and access to and sharing of educational information.

Through WhatsApp, teachers can be more familiar with their students' limits and abilities of interaction. The average response to this statement is
(4.40) whereas the standard deviation is (0.78). This result was verified by a study made by [8] which examined the effect of the use of WhatsApp on English as Foreign Language (EFL) students in written vocabulary tasks in Saudi Arabia. The author found that WhatsApp had a positive effect on students' performances. The students enjoyed using WhatsApp as a learning tool.

WhatsApp creates a friendly relationship between the teacher and the students. The average responses to this statement (4.35) whereas the standard deviation is (0.83). This result was strongly backed up by [3] which examined college of education students' experiences of WhatsApp mobile learning and found that the use of WhatsApp increased students' social interactivity with each other and with the instructor, and this facilitated collaborative learning.

WhatsApp can help teachers observe and control the progress of their students. The average response to this statement is (4.25) whereas the standard deviation is (0.90). This result was also supported by a study carried out by [20] that the use of WhatsApp to facilitate blended learning had a positive and significant impact on students' learning performance and their attitudes toward blended learning.

WhatsApp puts the students with their teacher in a constant communicative setting. The average response to this statement is (4.15) whereas the standard deviation is (0.70).

WhatsApp is an efficient tool of interaction in cases of distant learning. The average response to this statement is (4.08) whereas the standard deviation is (1.02). Therefore, student-teacher interaction becomes more effective in WhatsApp than inside the classroom. The average response to this statement is (3.83) whereas the standard deviation is (1.08).

\section{Conclusion and Recommendations}

The previous research has shown that WhatsApp has several technological, social, and pedagogical advantages. These studies have shown that WhatsApp is popular among university students and that students use it constantly for different purposes in different parts of the world. These advantages and WhatsApp's popularity suggest that it could be used to support students' formal learning, particularly in becoming an interactive and communicative tool between the students and their teachers. The current study also found The results show that WhatsApp had a positive effect in enhancing interaction between students and their teachers, WhatsApp makes interaction between teachers and their students easier than in the classroom. As a result, shy students can freely communicate and interact through WhatsApp with each other and their teachers, WhatsApp creates a friendly relationship 
between students and their teacher, and WhatsApp is an efficient tool of interaction in cases of distant learning. Therefore, student-teacher interaction becomes more effective in WhatsApp than inside the classroom.

The most common use of WhatsApp for academic purposes among the participants was to communicate with each other and teachers on matters related to their academic purposes. However, the participants had positive perceptions of the formal use of WhatsApp to support their teacherstudents rapport and interaction. They believed the integration of WhatsApp into their academic field would be easy, fun, and useful. They had positive feelings and intentions regarding the possible use of WhatsApp in their formal learning. However, the participants were optimistic about the social acceptance of the use of WhatsApp in their academic fields.

The findings of this study suggest that the use of the WhatsApp would facilitate communication between students, and between students and their teachers, and it would cater for collaborative learning through the creation of electronic groups. The formal integration of WhatsApp into university students' learning environment requires considering the students' social constraints and privacy.

Further studies are required to improve understanding in relation to the use of WhatsApp in university students' learning. The findings of the current study have shown that the use of WhatsApp as a student-teacher interactive tool at the university level can be accepted by the students and teachers. However, future research should address students' perceptions and attitudes towards specific uses of WhatsApp in their academic environments. In addition, there is an urgent need for empirical studies that investigate the influence of WhatsApp's use on students' academic performance.

\section{References}

[1] Al-Rahmi, W. M., \& Othman, M. S. (2015). The Impact of Social Media use on Academic Performance among university students: A Pilot Study. Journal Of Information Systems Research and Innovation.

[2] Bouhnik, D., \& Deshen, M. (2014). WhatsApp Goes to School: Mobile Instant Messaging between Teachers and Students. Journal of Information Technology Education: Research, 13, 217-231. Retrieved from http://www.jite.org/documents/Vol13/JITEv13ResearchP2 17-231Bouhnik0601.pdf.

[3] Bsharah, M., Gasaymeh, A. M., \& Abdelrahman, M. B. (2014). The Relationship between the Use of Social Networking Sites (SNS) and Perceived Level of Social Intelligence among Jordanian University Students: The Case of Facebook. International Journal of Psychological Studies, 6(3), 1.
[4] Hamade, S. N. (2013). Perception and use of social networking sites among university students. Library Review, 62(6/7), 388-397.

[5] Karpinski, A. C., Kirschner, P. A., Ozer, I., Mellott, J. A., \& Ochwo, P. (2013). An exploration of social networking site use, multitasking, and academic performance among the United States and European university students. Computers in Human Behavior, 29(3), 1182-1192.

[6] Vorderer, P., Krömer, N., \& Schneider, F. M. (2016). Permanently online-Permanently connected: Explorations into university students' use of social media and mobile smart devices. Computers in Human Behavior, 63, 694703.

[7] Raza, S. A., Qazi, W., \& Umer, A. (2017). Facebook Is a Source of Social Capital Building Among University Students: Evidence From a Developing Country. Journal of Educational Computing Research, 55(3), 295-322.

[8] Acheaw, M. O., \& Larson, A. G. (2015). Use of Social Media and its Impact on Academic Performance of Tertiary Institution Students: A Study of Students of Koforidua Polytechnic, Ghana. Journal of Education and Practice, 6(6), 94-101.

[9] Olaleke, J. O., Iroju, O. G., \& Olajide, M. S. (2015). An Assessment of the Use of Online Social Network Sites for Enhancing Computing Students' Academic Activities. Journal of Scientific Research and Reports, 5, 489-499.

[10] Cetinkaya, L. (2017). The Impact of Whatsapp Use on Success in Education Process. The International Review of Research in Open and Distributed Learning, 18(7).

[11] Van Doorn, G., \& Eklund, A. A. (2013). Face to Facebook: Social media and the learning and teaching potential of symmetrical, synchronous communication. Journal of University Teaching \& Learning Practice, 10(1), 1-16.

[12] Georgieva, V. (2014). The Digital Natives in the New Age. Trakia Journal of Sciences, 12(4), 367.

[13] Husain, R., \& Adamu, A. (2014). Social networking site as a tool to enhance the educational communication between teacher and students. Scholarly Journal of Education, 3(8), 101-105.

[14] Yin, L. C. (2016). Adoption of WhatsApp instant messaging among students in Ipoh Higher Education Institutions. Retrieved 1 25, 2018, from http://woulibrary.wou.edu.my/thesesproject/MED2016_CYLEE.pdf.

[15] Gachago, D., Strydom, S., Hanekom, P., Simons, S., \& Walters, S. (2015). Crossing boundaries: lectures' perspectives on the use of WhatsApp to support teaching and learning in higher education. Progressio, 37 (1), 172187.

[16] Chipunza, P. R. C. (2013). Using mobile devices to leverage student access to collaboratively generated resources: A case of WhatsApp instant messaging at a 
South African University. In International Conference on Advanced Information and Communication Technology for Education ICAICTE.

[17] Tarighat, S., \& Khodabakhsh, S. (2016). MobileAssisted Language Assessment: Assessing speaking. Computers in Human Behavior, 64, 409413.

[18] Alsaleem, B. I. A. (2013). The effect of "WhatsApp" electronic dialogue journaling on improving writing Vocabulary Word Choice and Voice of EFL Undergraduate Saudi Students. Arab World English Journal, 4(3), 213-225.

[19] Ngaleka, A., \& Uys, W. (2013, June). M-learning with WhatsApp: A conversation analysis. In International Conference on e-Learning (p. 282). Academic Conferences International Limited.

[20] Barhoumi, C. (2015). The Effectiveness of WhatsApp Mobile Learning Activities Guided by Activity Theory on Students' Knowledge Management. Contemporary Educational Technology, 6(3), 221-238.

[21] Bansal, T., \& Joshi, D. (2014). A study of students experiences of WhatsApp mobile learning. Global Journal of Human-Social Science Research, 14(4).

[22] Bere, A. (2013). Using mobile instant messaging to leverage learner participation and transform pedagogy at a South African University of Technology. British Journal of Educational Technology, 44(4), 544-561.

[23] Tang, Y., \& Hew, K. F. (2017). Is mobile instant messaging (MIM) useful in education? Examining its technological, pedagogical, and social affordances. Educational Research Review. Retrieved June 8, 2017, from http://www.sciencedirect.com/science/article/pii/ S0747563216305039.

[24] Yeboah, J., \& Ewur, G. D. (2014). The impact of WhatsApp messenger usage on students' performance in Tertiary Institutions in Ghana. Journal of Education and practice, 5(6), 157-164.

[25] Malecela, I. O. (2016). Usage of Whatsapp among Postgraduate Students of Kulliyyah of Education, International Islamic University Malaysia. International Journal of Advanced Engineering Research and Science.

[26] So, S. (2016). Mobile instant messaging support for teaching and learning in higher education. The Internet and Higher Education, 31, 32-42. 